\title{
"Sweeter than a rose", at least to Triatoma phyllosoma complex males (Triatominae: Reduviidae)
}

\author{
Irving J. May-Concha ${ }^{1,2}$, Leopoldo C. Cruz-López ${ }^{3}$, Julio C. Rojas ${ }^{3}$ and Janine M. Ramsey ${ }^{1 *}$
}

\begin{abstract}
Background: The Triatoma phyllosoma complex of Trypanosoma cruzi vectors (Triatominae: Reduviidae) is distributed in both Neotropical and Nearctic bioregions of Mexico.

Methods: Volatile organic compounds emitted by disturbed Triatoma longipennis, Triatoma pallidipennis and Triatoma phyllosoma, and from their Brindley's and metasternal glands, were identified using solid-phase microextraction coupled with gas chromatography-mass spectrometry.

Results: Disturbed bugs and the metasternal glands from T. phyllosoma released or had significantly fewer compounds than T. longipennis and T. pallidipennis. Isobutyric acid was the most abundant compound secreted by disturbed bugs of the three species, while Brindley's glands of all species produced another four compounds: propanoic acid, isobutyric acid, pentyl butanoate, and 2-methyl hexanoic acid. Two novel compounds, both rose oxide isomers, were produced in MGs and released only by disturbed females of all three species, making this the first report in Triatominae of these monoterpenes. The principal compound in MGs of both sexes of T. longipennis and T. phyllosoma was 3-methyl-2-hexanone, while cis-rose oxide was the principal compound in T. pallidipennis females. The major components in male effluvia of T. pallidipennis were 2-decanol and 3-methyl-2-hexanone.
\end{abstract}

Conclusion: Discriminant analysis of volatile organic compounds was significant, separating the three species and was consistent with morphological and genetic evidence for species distinctions within the complex.

Keywords: Phyllosoma complex, Exocrine glands, Volatile compounds, Chemotaxonomy

\section{Background}

Insects release a wide range of volatile organic compounds (VOCs) into the environment, which may have communicative functions acting as semiochemicals, while others may be metabolic by-products, albeit precursors, for evolving purposeful communication [1]. VOCs are produced in specialized cells, exocrine glands, or by associated microorganisms [2, 3], and may differ in chirality or ratio in closely related insect species [4]. Pheromone composition may vary within populations of the same species, but they may also be associated with species-specific recognition [5]. Nonetheless, pheromone compounds used by closely related species have structural similarities, suggesting common

\footnotetext{
* Correspondence: jramsey@insp.mx

${ }^{1}$ Centro Regional de Investigación en Salud Pública, Instituto Nacional de

Salud Pública (CRISP-INSP), Tapachula, Chiapas, Mexico

Full list of author information is available at the end of the article
}

biosynthetic pathways [5]. As a result, VOC profiles can be used as characters for phylogenetic inferences $[6,7]$.

Triatomine bugs have two principal exocrine glands: the Brindley's (BGs) and the metasternal (MGs) glands [8]. Previous studies demonstrated that these glands in some triatomines produce and release VOCs for alarm and sexual behaviour [9-12]. BGs of most triatomines primarily release isobutyric acid, a highly conserved compound in both North and South American subclades of the Triatomini [13]. In contrast, MGs produce multiple ketones and alcohols, most of which are species-specific $[10-12,14,15]$. A recent study comparing exocrine volatiles among the three primary dimidiata complex haplogroups demonstrated subtle but specific differences in production and secretion of VOCs between sister species [12]. 
One of the largest and epidemiologically important triatomine species complexes in North America, is the Triatoma phyllosoma complex [16-19]. It only occurs in Mexico, broadly distributed from the northeastern Nearctic through to the northern Neotropical bioregion of Mexico, west of the Tehuantepec Isthmus/Chimalapas forest. Species of the phyllosoma complex are principal vectors of Trypanosoma cruzi in sylvatic and synanthropic habitats in Mexico, due to their broad opportunism for biotic interactions, and their amplification in modified habitats [20-24]. The most widely accepted taxonomic revision of the Triatominae returned all sub-species of the phyllosoma complex (described to that date) to species-level classification based on classical morphology (i.e. T. phyllosoma, T. picturata, T. pallidipennis, $T$. longipennis and $T$. mazzottii) [16]. Three subsequently described species were added ( $T$. brailovskyi, T. bolivari, T. bassolsae), and three further species were included in the complex based on molecular evidence ( $T$. gerstaeckeri, $T$. recurva and $T$. mexicana) $[18,19,25]$. In many regions, two or more species of the complex are sympatric, and although there is clear reproductive exclusion (after backcrossing), successful first- and second-generation reproduction between species has been reported ([26, 27], J. Ramsey, personal communication).

Given significant differences in VOC concentrations and aggregation or alarm behaviour among species of the closely related dimidiata complex, we hypothesized that VOC profiles would be similar in the phyllosoma complex species. Geographically, $T$. pallidipennis and $T$. longipennis are sympatric across part of their distributions, while T. phyllosoma is allopatric to both, which could have an impact on production or expression of conserved VOCs. Additionally, given novel VOCs identified in all dimidiata complex haplogroups, we also hypothesized that the phylogenetically close phyllosoma complex would share these or similar novel compounds. Alarm pheromones may give rise to a plethora of secondary compounds and behaviours, and hence by focusing on understanding disturbed behaviour, complex interactions which specifically affect speciation or population dynamics, such as improved vector fitness in modified habitats, can be analyzed. VOCs emitted by disturbed adults of $T$. pallidipennis, $T$. longipennis and $T$. phyllosoma, as well as those produced by their BGs and MGs, are therefore important not only to provide complementary genetic and ethological characters to understand speciation drivers and phylogeography, but their understanding is essential to develop effective and sustainable control tools effective for specific eco-demographic patterns related to land use and vector exposure potential [28].

\section{Methods}

\section{Triatomine populations tested}

Triatoma pallidipennis, $T$. longipennis and $T$. phyllosoma colonies were established at the Centro Regional de Investigación en Salud Pública (CRISP/ INSP) from collection sites where species are not sympatric. Triatoma pallidipennis was colonized using individuals collected across the state of Morelos, while the $T$. longipennis colony was derived from specimens from Zacatecas state, the only region where it is not sympatric with another species of the phyllosoma complex. Triatoma phyllosoma was collected from Pacific coast collection sites surrounding the Tehuantepec Isthmus (Salina Cruz, Ixtepec, Mexico). All colonies were bred to no more than four generations before new individuals from original sites were introduced to breeding pairs. All were maintained at $27 \pm 2{ }^{\circ} \mathrm{C}, 70 \pm 5 \% \mathrm{RH}$, and a photoperiod of 12:12 (Light:Dark). New Zealand White (NZW) rabbits were used as a blood meal source for all bugs, and these latter were fed eight days before sampling their volatiles. Fifth-stage nymphs were maintained separately and sexed once emerged, in single-sex cohorts, to ensure that adult insects used in the experiments were virgins. Experiments were performed with adults between 15 and 30 days after emergence. Each insect was sampled only once.

\section{Volatile sampling and chemical analyses}

Volatiles emitted by triatomines, and those produced by MGs and BGs were sampled using solid phase microextraction devices (SPME) fitted with fibers coated with $65 \mu \mathrm{m}$ polydimethylsiloxane-divinylbenzene (PDMS-DVB; Supelco, Belfonte, PA, USA). Previous studies have shown that this fiber efficiently samples the volatile compounds emitted by triatomine bugs $[11,12]$. The fiber was exposed to the insect headspace for $60 \mathrm{~min}$, and all samples were maintained at the same temperature and relative humidity $\left(25 \pm 2{ }^{\circ} \mathrm{C}\right.$ and $\left.65 \pm 10 \% \mathrm{RH}\right)$. In all experiments, control using the same conditions was performed before each test, using an empty flask. After the sampling period, the fiber was withdrawn and inserted into the injector of a gas chromatograph-mass spectrometer (GC-MS). The samples were desorbed for $1 \mathrm{~min}$ in the GC injector for analysis.

GC-MS analyses were performed with a GC Varian model CP-3800 equipped with a polar CP-wax $57 \mathrm{CB}$ capillary column $(25 \mathrm{~m}$ by $0.32 \mathrm{~mm}$, and $0.20 \mu \mathrm{m}$ coat thickness) coupled with a Varian Saturn 2200 mass spectrometer (Varian, Palo Alto, CA, USA). The oven temperature was programmed for $40{ }^{\circ} \mathrm{C}(1 \mathrm{~min}$ hold $)$, then $10{ }^{\circ} \mathrm{C} \mathrm{min}{ }^{-1}$ to $75{ }^{\circ} \mathrm{C}(0 \mathrm{~min})$, then $15{ }^{\circ} \mathrm{C} \min ^{1}$ to $200{ }^{\circ} \mathrm{C}$, and held for $15 \mathrm{~min}$. The splitless mode was used for the injector with the inlet temperature set at $250{ }^{\circ} \mathrm{C}$. Helium was used as a carrier gas at $1.0 \mathrm{ml} \mathrm{min}{ }^{-1}$. Ionization was by electron impact at $70 \mathrm{eV}$. The compounds identified had 
relative abundance $\geq 0.1 \%$ and were tentatively identified by matching the mass spectra of GC peaks with those in the MS library (NIST 2002). The identities of the compounds were confirmed by comparing retention times with mass spectra of synthetic standards. The relative abundance of a particular compound was calculated as the proportion of its area to all GC peak areas combined.

Standard compounds for most of those identified in the headspace of disturbed bugs and exocrine glands were obtained at $98-99.5 \%$ purity from commercial sources (Sigma-Aldrich, Toluca, Mexico). 3-methyl-2-hexanone and 3-methyl-2-pentanone were donated by Dr. William F. Wood (Chemistry Department, Humboldt State University, Arcata, CA, USA); 3,5-dimethyl-2-hexanone was donated by Dr. Joselyn G. Millar (Department of Entomology, University of California, Riverside, CA, USA). 3-methyl-2hexanol was prepared from 3- methyl-2-hexanone by reduction with sodium borohydride in methanol [29]. 1-octen-3-one was prepared by sodium hypochlorite oxidation of 1-octen-3-ol [29].

\section{Volatiles released by disturbed adults}

Volatiles released by disturbed and undisturbed adults of the three species were identified from replicates using either three females/group, or three males/group. Bugs were gently introduced into a $50 \mathrm{ml}$ borosilicate glass Erlenmeyer flask and the mouth of the flask covered with aluminum foil and sealed with masking tape. The experimental bugs were vigorously shaken for $30 \mathrm{~s}$, while control bugs were not. An SPME fiber was exposed immediately to the headspace through a pin-size hole in the top of the aluminum foil. After $60 \mathrm{~min}$, the fiber was withdrawn and inserted into the GC-MS injector. Ten replicates each of shaken or unshaken females or males were performed.

\section{Volatiles produced by BGs and MGs}

Volatile compounds from female and male BGs and MGs were identified in all $T$. phyllosoma complex species. Bugs were placed in a freezer at $-20{ }^{\circ} \mathrm{C}$ for $5 \mathrm{~min}$ to avoid spontaneous emptying of the glands during processing, and ten pairs of MGs and BGs from both females and males were dissected separately under sterile water using a binocular microscope. Glands were placed in pairs into a $2 \mathrm{ml}$ glass conical vial and the mouth of the vial covered with aluminum foil sealed with masking tape. The glands were crushed using a thin wire, which was introduced into the vial through a pinsize hole in the aluminum foil, an SPME fiber was then exposed to the headspace for $60 \mathrm{~min}$ after which the fiber was withdrawn and inserted into the GC-MS injector. Ten replicates of each sex, species, and type of gland were sampled.

\section{Statistical analyses}

Differences between VOCs released by disturbed adults and by exocrine glands among species were analyzed using univariate and multivariate methods. Means and standard deviations of abundance were calculated for each chemical compound. Since the variables were heteroscedastic, the Kruskall-Wallis non-parametric test was used for univariate analyses. The software PAD version 60 was used to compare differentially among the three species, or according to sex (10 males, 10 females for each species), for the compounds produced by MGs and BGs, or released by disturbed bugs. PAD uses a classical discriminant analysis to estimate non-parametric statistical significance (Wilks and Mahalanobis distance values) using a permutation test (1000 permutation) and uses crosschecked classification tests to validate the reclassification of discriminant analysis [30].

\section{Results}

\section{Volatiles released by disturbed adults}

Disturbed females from T. longipennis, T. pallidipennis and T. phyllosoma released 18, 13 and 8 compounds, respectively, while disturbed males emitted 16, 11 and 6 compounds, respectively (Table 1). The compounds 3-methyl-2-pentanone and isobutyric acid were common to both sexes of all three species, the latter accounting for $76-97 \%$ of the volatiles released by disturbed bugs. The compounds cis-rose oxide and trans-rose oxide were emitted only by females of all three species. Compounds $3,4,6,7,11,14$ and 16 were exclusively emitted by $T$. longipennis, while compounds 18,20 and 21 were found in the headspace only of $T$. pallidipennis and $T$. phyllosoma (Table 1). Triatoma phyllosoma disturbed bugs released significantly fewer compounds as compared to those released by $T$. pallidipennis and $T$. longipennis.

There were significant differences in the relative amounts of VOCs emitted by disturbed bugs among the three species $(H=42.75, d f=5, P=0.01)$. Disturbed females from the three species emitted significantly different amounts of 21 compounds $(H=19.35, d f=2, P$ $=0.03$ ). However, both sexes of $T$. longipennis released similar amounts of 6-methyl-2-heptanol $(H=0.46, d f=1$, $P=0.49)$ and 3-methyl-2-hexanol $(H=1.75, d f=1, P=$ 0.18 ), while there were no differences in the relative amounts of 3-methyl-2-pentanone $(H=2.64, d f=1, P=$ $0.10), \quad 1$-octen-3-one $(H=0.69, d f=1, \quad P=0.40)$, and decanal $(H=1.46, d f=1, P=0.22)$ emitted by male and female $T$. pallidipennis. There was no difference in the relative amount of 2-methyl hexanoic acid $(H=1.56, d f$ $=1, P=0.21$ ) released by either sex of $T$. phyllosoma, and there was no significant difference in 3-methyl-2pentanone $(H=19.38, d f=2, P>0.05), 1$-octen-3-one $(H$ $=19.46, d f=2, P>0.05)$, 3-methyl-2-hexanol $(H=23.08$, 
Table 1 Relative amount (in \%, mean \pm SE) of volatile compounds collected from the headspace of disturbed females and males of the three phyllosoma complex species

\begin{tabular}{|c|c|c|c|c|c|c|c|}
\hline \multirow[b]{2}{*}{ No. } & \multirow[b]{2}{*}{ Compound/Sex } & \multicolumn{2}{|c|}{ Triatoma longipennis } & \multicolumn{2}{|c|}{ Triatoma pallidipennis } & \multicolumn{2}{|c|}{ Triatoma phyllosoma } \\
\hline & & 우 & 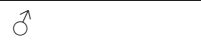 & q & $\hat{0}$ & q & $\hat{\sigma}$ \\
\hline 1 & 3-Methyl-2-pentanone & $0.37 \pm 0.04(7)$ & t & $0.51 \pm 0.08(6)$ & $0.32 \pm 0.04(7)$ & $0.05 \pm 0.02(9)$ & $0.11 \pm 0.03(8)$ \\
\hline 2 & 3-Methyl-2-hexanone & $2.77 \pm 0.31(10)$ & $0.89 \pm 0.16(8)$ & nd & nd & $0.77 \pm 0.30(9)$ & $3.89 \pm 0.97(10)$ \\
\hline 3 & 4-Methyl-2-heptanol & $0.11 \pm 0.01(8)$ & t & nd & nd & nd & nd \\
\hline 4 & 3,5-Dimethyl-2-hexanone & $0.56 \pm 0.03(7)$ & t & nd & nd & nd & nd \\
\hline 5 & 2-Methyl-3-pentanol & $0.4 \pm 0.04(8)$ & t & $0.03 \pm 0.01(8)$ & $1.47 \pm 0.34(10)$ & nd & nd \\
\hline 6 & 3,5-Dimethyl-2-hexanone isomer ${ }^{a}$ & $0.04 \pm 0.00(6)$ & $\mathrm{t}$ & nd & nd & nd & nd \\
\hline 7 & 6-Methyl-2-heptanol & $0.37 \pm 0.05(7)$ & $0.33 \pm 0.04(6)$ & nd & nd & nd & nd \\
\hline 8 & 2-Hexanol & $0.05 \pm 0.01$ & t & $0.31 \pm 0.07(7)$ & $1.52 \pm 0.42(10)$ & nd & nd \\
\hline 9 & 1-Octen-3-one & $0.97 \pm 0.21(7)$ & $0.31 \pm 0.03$ & $0.64 \pm 0.09(9)$ & $0.56 \pm 0.14(10)$ & nd & nd \\
\hline 10 & 3-Methyl-2-hexanol & $0.38 \pm 0.04(8)$ & $0.32 \pm 0.04(6)$ & $0.84 \pm 0.22(7)$ & $0.36 \pm 0.08(10)$ & nd & nd \\
\hline 11 & 3-Methyl-2-hexanol isomer ${ }^{a}$ & t & $0.11 \pm 0.02(6)$ & nd & nd & nd & nd \\
\hline 12 & cis-Rose oxide & $9.82 \pm 1.61(10)$ & nd & $7.53 \pm 1.17(10)$ & nd & $8.81 \pm 4.07(10)$ & nd \\
\hline 13 & trans-Rose oxide & $5.63 \pm 0.83(10)$ & nd & $5.62 \pm 2.06(10)$ & nd & $2.43 \pm 0.53(10)$ & nd \\
\hline 14 & 2-Nonanol & t & $0.69 \pm 0.12(7)$ & nd & nd & nd & nd \\
\hline 15 & 1-Octen-3-ol & $1.73 \pm 0.23(6)$ & $0.11 \pm 0.02(7)$ & $0.16 \pm 0.02(8)$ & $0.56 \pm 0.15(5)$ & nd & nd \\
\hline 16 & 3,5-Dimethyl-1-hexene & $\mathrm{t}$ & t & nd & nd & nd & nd \\
\hline 17 & Decanal & $0.86 \pm 0.16(7)$ & $\mathrm{t}$ & $2.36 \pm 0.5(7)$ & $3.04 \pm 0.69(8)$ & nd & nd \\
\hline 18 & Propanoic acid & nd & nd & $0.76 \pm 0.15(10)$ & $0.38 \pm 0.07(10)$ & $0.33 \pm 0.10(10)$ & $0.41 \pm 0.09(10)$ \\
\hline 19 & Isobutiryc acid & $75.78 \pm 3.16(10)$ & $96.77 \pm 0.43(10)$ & $77.24 \pm 5.11(10)$ & $90.34 \pm 2.11(10)$ & $87.23 \pm 4.83(10)$ & $94.73 \pm 1.21(10)$ \\
\hline 20 & Pentyl butanoate & nd & nd & $0.51 \pm 0.17(8)$ & $1.1 \pm 0.25(10)$ & $0.04 \pm 0.01(10)$ & $0.37 \pm 0.10(9)$ \\
\hline 21 & 2-Methyl hexanoic acid & nd & nd & $3.49 \pm 0.94(8)$ & $0.35 \pm 0.07(10)$ & $0.34 \pm 0.09(10)$ & $0.49 \pm 0.10(10)$ \\
\hline
\end{tabular}

${ }^{a}$ Compound that was not identified by comparison to pure standards

Note: Numbers in parentheses indicate the detection frequency for each compound ( $n=10$ samples)

Abbreviations: $t$, traces $(<0.1 \%$ abundance); $n d$, not detected

$d f=2, P>0.05)$, and isobutyric acid $(H=11.82, d f=2$, $P>0.05)$ concentrations between $T$. longipennis and $T$. pallidipennis. Female T. phyllosoma emitted significantly higher amounts of isobutyric acid in comparison to $T$. pallidipennis and $T$. longipennis females $(H=11.82, d f=$ 2, $P=0.002$ ), while $T$. longipennis males released significantly higher amounts of isobutyric acid than males of the other two species $(H=12.43, d f=2, P=0.002)$. Disturbed males secreted significantly different quantities of $19 / 21$ compounds $(H=23.28, d f=5, P=$ 0.001 ), with $T$. phyllosoma males releasing fewer compounds compared to T. pallidipennis and T. longipennis. There was no quantitative difference of pentyl butanoate $(H=22.43, d f=2, P>0.05)$ or 2-methyl hexanoic acid $(H=19.83, d f=2, P>0.05)$ between $T$. pallidipennis and T. phyllosoma males.

\section{Volatiles produced in GBs}

BGs of all three T. phyllosoma complex species emitted four compounds: propanoic acid, isobutyric acid, pentyl butanoate, and 2-methyl hexanoic acid (Table 2). The major compound from BGs of all three species was isobutyric acid, which was also the major compound in the effluvia of disturbed bugs (Table 1). There were interspecific differences of the four BG compounds among females of the three species $(H=10.54, d f=2, P=0.005)$. BGs of $T$. phyllosoma females released the highest amount of isobutyric acid $(H=19.40, d f=2, P=0.001)$, while there were no differences in the relative amounts of isobutyric acid $(H=19.09, d f=2, P>0.05)$, pentyl butanoate $(H=10.54, d f=2, P>0.05)$, or 2-methyl hexanoic acid $(H=22.00, d f=2, P>0.05)$ between females of T. longipennis and T. pallidipennis. Similarly, there were significant differences for all four BG compounds in males between species $(H=17.11, d f=2, P=0.001)$. Triatoma pallidipennis males released the highest amount of isobutyric acid, as compared to T. longipennis and $T$. phyllosoma $(H=18.40, \quad d f=2, \quad P=0.0001)$, whereas there was no difference in the relative amounts of pentyl butanoate $(H=16.11, d f=2, P>0.05)$ and 2-methyl hexanoic $(H=20.84, d f=2, \quad P>0.05)$ acid between these latter two species.

BGs from T. longipennis males had a higher amount of pentyl butanoate $(H=6.22, d f=1, P=0.01)$ than females. 
Table 2 Relative amount (\%, mean \pm SE) of volatile compounds in the effluvia of Brindley's glands of females and males of the three phyllosoma complex species

\begin{tabular}{|c|c|c|c|c|c|c|c|}
\hline \multirow[b]{2}{*}{ No } & \multirow[b]{2}{*}{ Compounds/sex } & \multicolumn{2}{|c|}{ Triatoma longipennis } & \multicolumn{2}{|c|}{ Triatoma pallidipennis } & \multicolumn{2}{|c|}{ Triatoma phyllosoma } \\
\hline & & q & 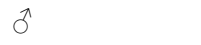 & q & $\hat{0}$ & q & $\hat{0}$ \\
\hline 1 & Propanoic acid & $4.11 \pm 0.69(10)$ & $3.69 \pm 0.45(10)$ & $0.67 \pm 0.11(10)$ & $2.81 \pm 0.45(10)$ & $0.91 \pm 0.16(10)$ & $5.82 \pm 1.10(10)$ \\
\hline 2 & Isobutyric acid & $90.35 \pm 2.46(10)$ & $92.56 \pm 0.63(10)$ & $91.05 \pm 1.94(10)$ & $96.31 \pm 0.53(10)$ & $98.15 \pm 0.19(10)$ & $88.01 \pm 1.67(10$ \\
\hline 3 & Pentyl butanoate & $0.56 \pm 0.12(10)$ & $0.72 \pm 0.08(10)$ & $0.63 \pm 0.24(10)$ & $0.11 \pm 0.01(10)$ & $0.25 \pm 0.03(10)$ & $0.59 \pm 0.14(10$ \\
\hline 4 & 2-Methyl hexanoic acid & $4.98 \pm 1.74(10)$ & $3.03 \pm 0.27(10)$ & $7.65 \pm 1.69(10)$ & $0.78 \pm 0.11(10)$ & $0.68 \pm 0.12(10)$ & $5.58 \pm 1.57(10)$ \\
\hline
\end{tabular}

Note: Numbers in parentheses indicate the detection frequency for each compound ( $n=10$ samples)

BGs from T. pallidipennis females had a higher amount of 2-methyl hexanoic acid $(H=14.29, d f=1, P=0.0002)$ than conspecific males, while in contrast, there were higher amounts of propanoic $(H=13.72, d f=2, P=$ $0.0002)$ and isobutyric acid $(H=7.82, d f=2, P=0.005)$ in males as compared to females of the same species. BGs from $T$. phyllosoma females contained more isobutyric acid $(H=14.29, d f=2, P=0.0002)$ than males, while BGs from the same species' males contained significantly higher amounts of propanoic $(H=14.29, d f=2, P=$ $0.0002)$ and 2-methyl hexanoic acid $(H=14.29, d f=2, P$ $=0.0002)$ in comparison to females.

\section{Volatiles contained in MGs}

MGs from $T$. longipennis, $T$. pallidipennis, and $T$. phyllosoma females contained 20, 19 and 17 compounds, respectively, while MGs from males contained 18, 17 and 15 compounds, respectively (Table 3 ). Five compounds (2, $5,11,17$ and 23) were present in more than trace quantities in both sexes of all three species. The principal MG compound in both sexes of T. longipennis and T. phyllosoma was 3-methyl-2-hexanone (compound 5). Although cis-rose oxide (compound 20) was the principal compound in $T$. pallidipennis females, the major components in effluvia of male MGs were 3-methyl-2-hexanone and 2-decanol. Compounds 3 and 4 were exclusively found in $T$. pallidipennis, while compounds 9, 13 and 22 were exclusively identified in $T$. longipennis. There was a significant difference in the relative amounts of $25 \mathrm{MG}$ compounds between females of the three species $(H=15.68, d f=2, P=$ $0.0004)$. MGs contained, however, only 17 of the 21 volatile compounds emitted by disturbed bugs (Table 1). Triatoma phyllosoma released the highest amount of 3-methyl-2-hexanone of the three species $(H=25.81, d f=2, P=0.0001)$, while $T$. longipennis and $T$. pallidipennis secreted similarly high amounts of 4-methyl-2-heptanol $(H=19.90, d f=2, P$ $>0.05$ ). There were also significant differences for 23 (of 25) compounds identified in male MGs between the three species $(H=25.81, d f=2, P=0.001)$. Triatoma phyllosoma male MGs had a significantly higher amount of 3-methyl2-hexanone $(H=23.69, d f=2, \quad P=0.0001)$, while the amounts of 1-octen-3-one were similar, between $T$. longipennis and $T$. pallidipennis $(H=20.90, d f=2, P>$ 0.05).

Interestingly, compounds 20 (cis-rose oxide) and 21 (trans- rose oxide) were only identified in female MGs of the three species. There were no significant differences in the compounds 3-methyl-2-hexanone $(H=0.01$, $d f=1, P=0.93)$, 4-methyl-2-heptanol $(H=0.37, d f=1, P$ $=0.54)$, and 6-methyl-2-heptanol $(H=0.37, d f=1, P=$ 0.52 ) between males and females of $T$. longipennis, whereas there was no significant difference for only 1octen-3-ol $(H=2.17, d f=1, P=0.14)$ between male and female $T$. pallidipennis. There were significant differences in the amounts of 3-methyl-2-pentanone $(H=$ 13.71, $d f=1, P=0.0002), 3-5$-dimethyl-2-hexanone $(H$ $=14.29, d f=1, P=0.0002), 1$-octen-3-one $(H=13.17, d f$ $=1, \quad P=0.0003)$, and decanal $(H=14.29, d f=1, P=$ 0.0002 ) between male and female $T$. phyllosoma.

\section{Intra-complex differences in disturbed, BG, and MG adult volatiles}

The first function of the linear discriminant analysis of 21 compounds from disturbed females explained 84.9\% of the total variation, and the second function explained $15.2 \%$. The Mahalanobis distances for females were significantly different among the three species $(P<0.0001)$, with the discriminant plot indicating that $T$. longipennis is the most distant from both $T$. pallidipennis and $T$. phyllosoma (Fig. 1a). The Mahalanobis distance (D2) for the female group centroid indicated that $T$. longipennis is more distant from $T$. pallidipennis (D2 $=23.52$ ), than from $T$. phyllosoma (D2 = 20.09), while $T$. pallidipennis was least distant from $T$. phyllosoma (D2 = 7.78) (Fig. 1a). The first discriminant function for disturbed males explained $74.4 \%$ of total variation, whereas the second function explained $25.6 \%$, and the Mahalanobis distances for males indicated significant differences among the three species $(P<0.01)$. The discriminant plot of disturbed males indicated that $T$. pallidipennis is most distant from T. longipennis and T. phyllosoma (Fig. 1b). The Mahalanobis distance (D2) for the male group centroids, indicated that T. pallidipennis is more distant from $T$. longipennis $(\mathrm{D} 2=9.07)$ than from $T$. phyllosoma 
Table 3 Relative amount (\%, mean \pm SE) of volatile compounds in the effluvia of Metasternal glands of females and males of the three phyllosoma complex species

\begin{tabular}{|c|c|c|c|c|c|c|c|}
\hline & & Triatoma longipen & & Triatoma pallidip & ennis & Triatoma phyllos & ma \\
\hline No & Compounds/sex & q & 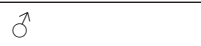 & 운 & 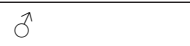 & q & $\hat{0}$ \\
\hline 1 & 2-Pentanone & $0.19 \pm 0.02(7)$ & $0.29 \pm 0.03$ & $0.1 \pm 0.02(6)$ & $1.33 \pm 0.12(7)$ & $0.15 \pm 0.02(6)$ & $\mathrm{t}$ \\
\hline 2 & 3-Methyl-2-pentanone & $5.58 \pm 0.41(8)$ & $9.94 \pm 0.90(7)$ & $3.11 \pm 0.47(8)$ & $12.56 \pm 0.86(8)$ & $8.63 \pm 1.11(8)$ & $2.42 \pm 0.42(7)$ \\
\hline 3 & 2-Butanol & nd & nd & $0.83 \pm 0.14(6)$ & $1.76 \pm 0.12(6)$ & nd & nd \\
\hline 4 & 2-Methyl-3-buten-2-ol & nd & nd & $0.49 \pm 0.06(8)$ & $1.19 \pm 0.12(8)$ & nd & nd \\
\hline 5 & 3-Methyl-2-hexanone & $34.65 \pm 1.72(10)$ & $45.48 \pm 3.07(10)$ & $8.93 \pm 0.94(10)$ & $18.52 \pm 2.34(9)$ & $73.99 \pm 0.08(9)$ & $90.84 \pm 1.12(9)$ \\
\hline 6 & 4-Methyl-2-heptanol & $1.1 \pm 0.06(7)$ & $1.44 \pm 0.09(8)$ & $1.35 \pm 0.15(6)$ & $3.1 \pm 0.56(7)$ & nd & nd \\
\hline 7 & 3,5-Dimethyl-2-hexanone & $3.57 \pm 0.30(8)$ & $3.14 \pm 0.26(7)$ & $0.44 \pm 0.06(7)$ & $2.69 \pm 0.23(8)$ & $t$ & $1.2 \pm 0.13(7)$ \\
\hline 8 & 2-Methyl-3-pentanol & $4.44 \pm 0.23(9)$ & $1.75 \pm 0.13(6)$ & $1.03 \pm 0.08(8)$ & $4.82 \pm 0.58(7)$ & nd & nd \\
\hline 9 & 4-Methyl-2-pentanol & $0.15 \pm 0.01$ & $0.17 \pm 0.02(5)$ & nd & nd & nd & nd \\
\hline 10 & 3,5-Dimethyl-2-hexanone isomer ${ }^{\mathrm{a}}$ & $0.12 \pm 0.01(8)$ & $0.17 \pm 0.02(8)$ & nd & nd & $0.2 \pm 0.04(8)$ & $0.84 \pm 0.13(7)$ \\
\hline 11 & 6-Methyl-2-heptanol & $13.42 \pm 1.01(6)$ & $17.57 \pm 1.18(7)$ & $2.95 \pm 0.16(6)$ & $1.15 \pm 0.14(5)$ & $0.4 \pm 0.07(7)$ & $2.91 \pm 0.40(8)$ \\
\hline 12 & 2-Methyl-1-butanol & nd & nd & $1.11 \pm 0.20(7)$ & $3.6 \pm 0.51(6)$ & $t$ & $\mathrm{t}$ \\
\hline 13 & 5-Methyl-2-heptanol & $0.1 \pm 0.01(7)$ & $0.15 \pm 0.02(6)$ & nd & nd & nd & nd \\
\hline 14 & 2-Hexanol & $0.16 \pm 0.01(9)$ & $0.49 \pm 0.04(7)$ & $0.4 \pm 0.03(8)$ & $3.58 \pm 0.45(7)$ & nd & nd \\
\hline 15 & 2-Heptanol & nd & nd & nd & nd & $0.22 \pm 0.04(6)$ & $t$ \\
\hline 16 & 1-Octen-3-one & $1.8 \pm 0.19(10)$ & $1.48 \pm 0.12(9)$ & $0.61 \pm 0.05(9)$ & $1.55 \pm 0.20(9)$ & $0.28 \pm 0.03(8)$ & $t$ \\
\hline 17 & 3-Methyl-2-hexanol & $0.37 \pm 0.05(10)$ & $7.87 \pm 1.40(9)$ & $4.79 \pm 0.05(9)$ & $13.35 \pm 1.45(8)$ & $1.04 \pm 0.17(9)$ & $0.9 \pm 0.18(8)$ \\
\hline 18 & 3-Methyl-2-hexanol isomer ${ }^{a}$ & $0.18 \pm 0.01(6)$ & $0.41 \pm 0.05$ & $0.68 \pm 0.89(7)$ & $1.74 \pm 0.17(6)$ & $0.1 \pm 0.01(7)$ & $t$ \\
\hline 19 & 2-Decanol & nd & nd & $3.67 \pm 0.04(6)$ & $19.65 \pm 1.77(7)$ & $0.25 \pm 0.06(5)$ & $0.2 \pm 0.04(8)$ \\
\hline 20 & cis-Rose oxide & $10.87 \pm 0.41(10)$ & nd & $44.42 \pm 0.53(8)$ & nd & $11.25 \pm 0.83(8)$ & nd \\
\hline 21 & trans-Rose oxide & $3.84 \pm 0.41(10)$ & nd & $17.66 \pm 2.58(9)$ & nd & $2.43 \pm 0.43(9)$ & nd \\
\hline 22 & 2-Nonanol & $1.24 \pm 0.13(7)$ & $6.69 \pm 0.1(6)$ & nd & nd & nd & nd \\
\hline 23 & 1-Octen-3-ol & $16.27 \pm 1.79(9)$ & $6.69 \pm 0.63(7)$ & $3.03 \pm 0.10(7)$ & $3.49 \pm 0.41(8)$ & $0.12 \pm 0.01$ & $0.11 \pm 0.03$ \\
\hline 24 & 3,5-Dimethyl-1-hexene & $0.18 \pm 0.01$ & $0.84 \pm 0.06(9)$ & nd & nd & $0.19 \pm 0.02(7)$ & $0.14 \pm 0.03(7)$ \\
\hline 25 & Decanal & $1.78 \pm 0.11(10)$ & $1.44 \pm 0.14(9)$ & $4.41 \pm 0.50$ & $5.92 \pm 0.48(9)$ & $1.15 \pm 0.12(8)$ & $\mathrm{t}$ \\
\hline
\end{tabular}

${ }^{a}$ Compounds not identified by comparison to pure standards

Note: Numbers in parentheses indicate the detection frequency for each compound ( $n=10$ samples)

Abbreviations: $\mathrm{t}$, traces $(<0.1 \%$ abundance); nd, not detected

(D2 = 6.83), whereas $T$. phyllosoma males were least distant to T. longipennis (D2 = 5.66) (Fig. 1b).

The first function of the linear discriminant analysis of the four female BG compounds explained $90.7 \%$ of total variation, whereas the second function explained $9.3 \%$. The Mahalanobis distances for females among the three species differed significantly $(P<0.0001)$, and the discriminant plot separated T. longipennis from T. pallidipennis, and the former from T. phyllosoma (Fig. 2a). The Mahalanobis distance (D2) based on female group centroids was greater between $T$. longipennis and T. pallidipennis (D2 = 5.02) as compared to the former and T. phyllosoma (D2 = 2.99), while $T$. pallidipennis was closest to T. phyllosoma (D2 = 2.79) (Fig. 2a). The first linear discriminant function for male BGs explained $80.8 \%$ of total variation, whereas the second function explained 19.2\%. The Mahalanobis distances for males were not significantly different between $T$. longipennis and $T$. phyllosoma $(P>0.01)$; the greatest distance for males was between $T$. pallidipennis and T. longipennis, as well as the former and $T$. phyllosoma $(P<0.0001)$. The Mahalanobis distance (D2) for male group centroids was greatest between $T$. pallidipennis and T. phyllosoma (D2 $=2.88)$, followed by the former to $T$. longipennis (D2 =2.29), while $T$. phyllosoma males were closest to $T$. longipennis males (D2 = 1.60) (Fig. 2b).

Linear discriminant analysis of MGs between males and females included 25 compounds. The first discriminant function explained $90.3 \%$ of the total variation for females, whereas the second function for females explained 9.3\%. The Mahalanobis distances for females were significantly different among the three species $(P<$ 0.0001), with $T$. pallidipennis being the most distant from T. longipennis and T. phyllosoma (Fig. 3a). The 


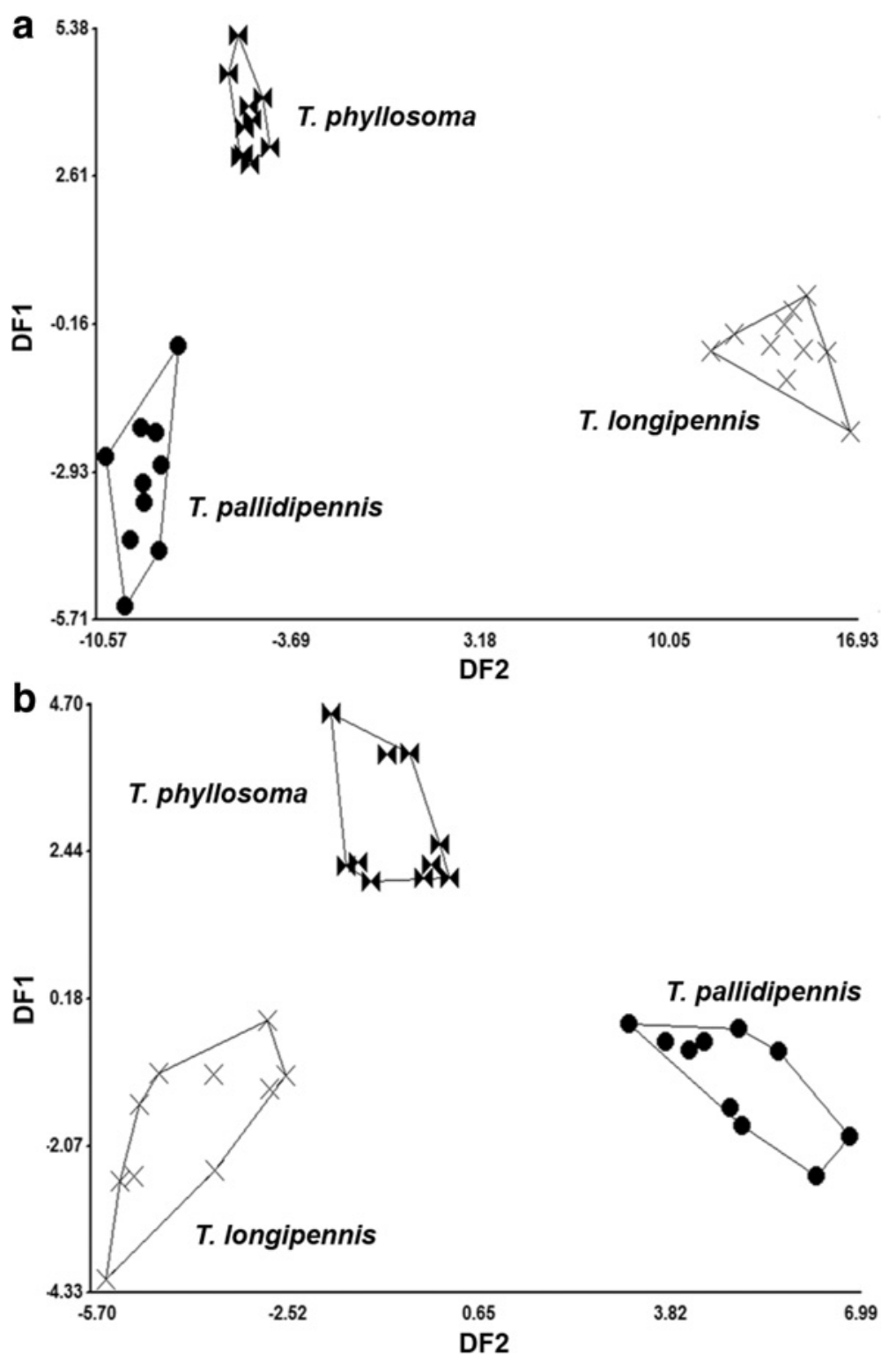

Fig. 1 Discriminant analysis of volatiles released by disturbed adults of species of the phyllosoma complex. a Females. b Males. Each point represents one specimen on the canonical axis. Polygons enclose specimens of each species. DF1 and DF2 represent the discriminant function 1 and 2 , respectively

Mahalanobis distance (D2) for the female group centroids, indicated that $T$. pallidipennis was more distant from $T$. longipennis $(\mathrm{D} 2=32.00)$ than from $T$. phyllosoma (D2 = 31.09), while $T$. phyllosoma was closest to $T$. longipennis (D2 = 20.22) (Fig. 3a). The first discriminant function for male MGs explained $99.3 \%$ of total variation, whereas the second function explained $0.7 \%$. The Mahalanobis distances for males were significantly different among the three species $(P<0.0001)$, with $T$. phyllosoma the most distant from both $T$. longipennis and T. pallidipennis (Fig. 3b). The Mahalanobis distance (D2) for the male group centroids indicated that $T$. phyllosoma is more distant from $T$. pallidipennis (D2 = 17.50) than from $T$. longipennis (D2 $=14.25)$, while $T$. pallidipennis was closest to $T$. longipennis $(\mathrm{D} 2=14.19)$ (Fig. 3b).

\section{Discussion}

There are qualitative and quantitative differences in VOCs emitted by disturbed bugs, and produced by exocrine glands, among the three phyllosoma complex species. The compound profiles differ between sexes of all three species; T. phyllosoma released significantly fewer VOCs than the other two northern and sympatric 

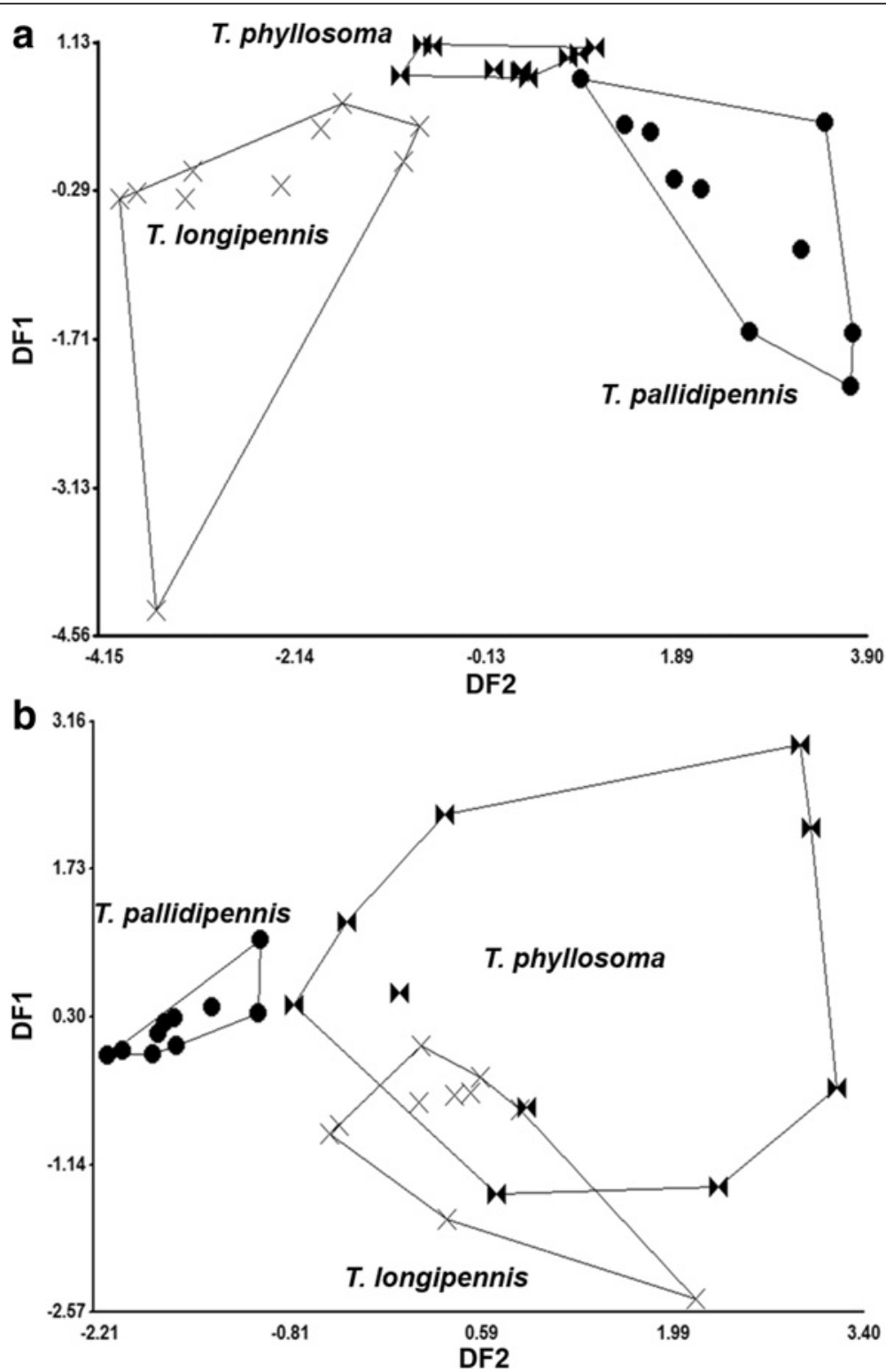

Fig. 2 Discriminant analysis of compounds identified in GBs in species of the phyllosoma complex. a Females. b Males. Each point represents one specimen on the canonical axis. Polygons enclose specimens of each species. DF1 and DF2 represent the discriminant function 1 and 2, respectively

species. Triatoma phyllosoma, allopatric with $T$. longipennis and T. pallidipennis is confined to lower altitudes immediately east and south of the Zapotecan foothills west of the Tehuantepec Isthmus, in a geographically confined semi-arid region along the Pacific coast of Oaxaca in Mexico. This species is only sympatric with $T$. dimidiata haplogroup 2 in this region $[19,24]$.

Despite vast latitudinal and altitudinal differences among the distributions of the three species of the phyllosoma complex, and hence important host species turnover, all three species produced and secreted the rose oxide compounds [19]. This unique phenotype was independent of the biogeographical region (Neotropical and Nearctic) or allopatry, since it was conserved in all three species. It is interesting that both closely related $T$. phyllosoma and $T$. dimidiata complexes have independently (and recently) developed distinct unique specific VOC communication compounds. In both complexes, they are conserved through speciation, although species-level and genderspecific concentration, behaviour, or receptor differences occur between species [31].

The phyllosoma complex MGs contained, depending on the species, between 17 and 25 compounds each, nine of which were also identified from the dimidiata complex, which provides additional evidence for their 


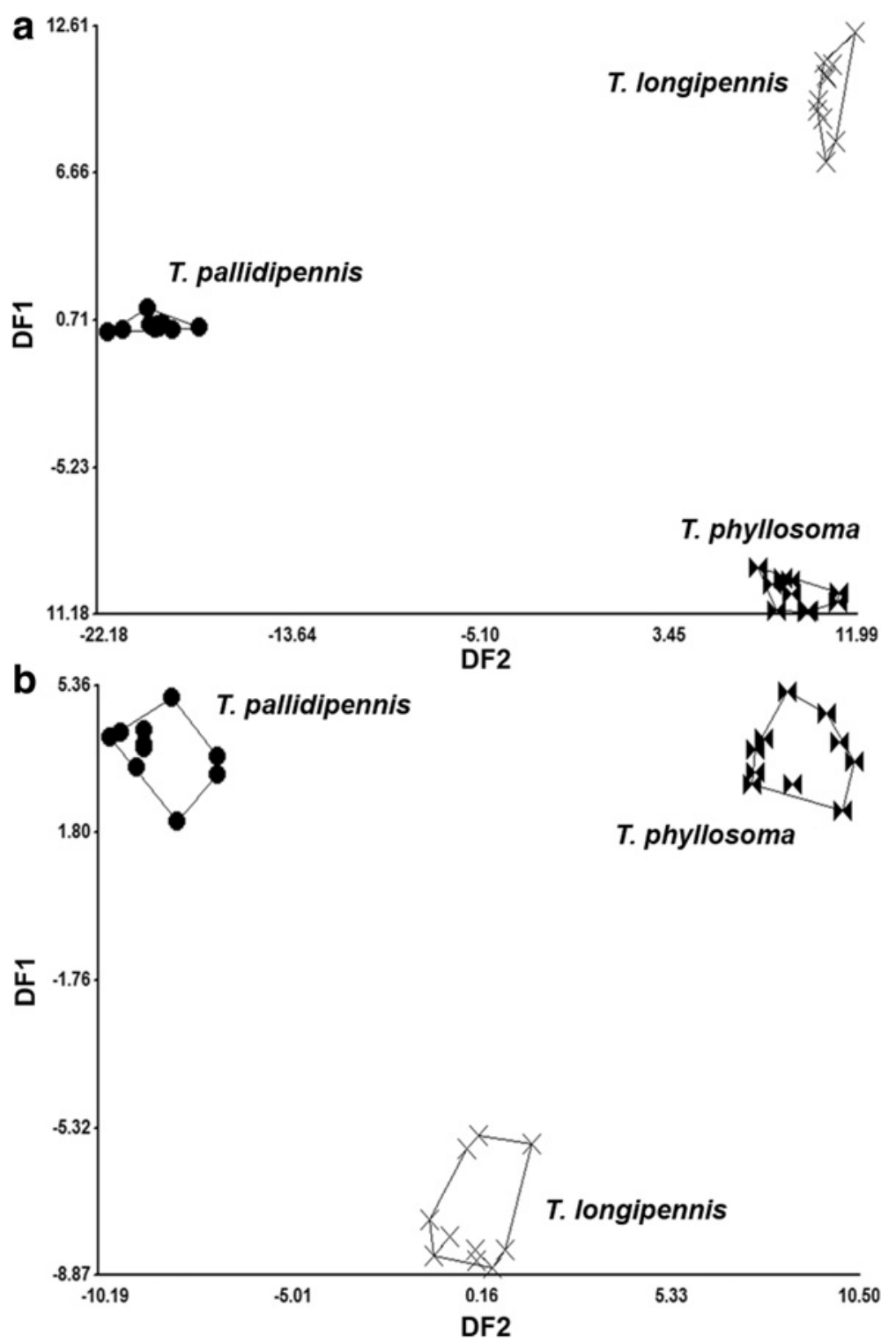

Fig. 3 Discriminant analysis of compounds identified in MGs in species of the phyllosoma complex. a Females. b Males. Each point represents one specimen on the canonical axis. Polygons enclose specimens of each species. DF1 and DF2 represent the discriminant function 1 and 2, respectively

close phylogenetic relationships [12, 25, 32]. Approximately $80 \%$ (17) of VOCs emitted by disturbed bugs were produced by MGs, although 10 additional MG compounds were not secreted by disturbed bugs. Some of these compounds have also been identified in the headspace of $T$. dimidiata mating pairs, one of which, 3-methyl-2-hexanone, was attractive for conspecific males [11]. 3-Methyl-2-hexanone has also been reported from MGs of D. maximus [33], a closely-related species, while 3-methyl-2-hexanol has been reported from $T$. brasiliensis [15, 34]. The compound 2-methyl-3-buten2-ol is conserved at the tribal level, having been reported from Rhodnius prolixus of the Rhodniini [14].
Rose oxide compounds have been reported in plants such as Rosa damascena Mill [35], Pelargonium graveolens Ait [35], Ribes nigrum Linnaeus [36], Hamanasu sp. [37] and Physalis peruviana Linnaeus [38]. In insects, rose oxide isomers have been reported from the secretions of two coleopterans, for which they are thought to have a defensive function [39-41]. They have also been reported, although not for alarm, from Melipona beecheii [42]. In the Triatominae [33] and Cerambycidae [43], the paired MG is located in the thorax and has reservoirs with openings near the articulated coxa of the hind legs. The oxide isomers may, therefore in females of the phyllosoma complex, function during 
copula, similar to that observed in some cerambycids which emit defensive semiochemicals from MGs [39, 40]. Although the relationship between chirality and behaviour-modifying chemicals perceived through olfaction has been studied in insects [44], the impact of chirality on insect behaviour and for specific activities has not been analyzed. In triatomines, the two novel enantiomers, the cis and trans isomers of rose oxide, represent a paradigm for olfactory-guided behaviour. These female-specific compounds may act as sexual and alarm pheromones, or as early warning signals of predators, hypotheses currently being analyzed [41, 45].

One of the major BG components of the blend emitted by disturbed bugs, from all three species, was isobutyric acid. This compound has been reported as a major component from disturbed $T$. infestans $[10,46,47], R$. prolixus and D. maximus [48], the dimidiata complex [12], and other hematophagous arthropods such as ticks [49]. Isobutyric acid was the most abundant BG compound in all species of the phyllosoma complex, as in several other triatomine species $[8,12,50,51]$. Some studies propose a role for isobutyric acid in alarm and defense $[10,12,47,52,53]$, in addition to its involvement in sexual communication [11, 48, 54]. Pentyl butanoate has also been reported in bedbugs of the genus Cimex, while hexanoic acid has been reported in certain Diptera, as alarm compounds $[55,56]$. Pentyl butanoate and 2-methyl hexanoic acid were identified in BGs of all $T$. dimidiata haplogroups, although neither has been reported from disturbed bugs of any other triatomine species [12]. Both T. pallidipennis and T. phyllosoma secreted these compounds when agitated, but they were not secreted by disturbed T. longipennis, even though the latter species produces the compounds in BGs. Propanoic acid is a repellent for grain storage beetles and weevils, is secreted by Coleoptera, some aphids, and has also been reported from disturbed adult $R$. prolixus and T. infestans $[47,48,56]$.

Behaviourally, disturbed $T$. pallidipennis and $T$. phyllosoma emitted similar compounds, both dissimilar to those from T. longipennis. Additionally, this latter species emitted twice as many MG compounds when disturbed (17), compared to either of the former. Although phenetic analyses have until now reported minimal differences among species of the phyllosoma complex, despite phylogenetic inferences using ITS2, cytb, and RAPD [25, $57,58]$, this was assumed to be due to recent divergence (1-10 my) [59-62]. Similar to morphometric differences which are expected when populations select for specific behaviours and micro-environmental conditions (host nest types, geography and climate), the degree and nature of landscape modification and fragmentation patterns may also be drivers of population diversification. Analysis of VOCs in other species of the phyllosoma complex, and the remaining North American species complexes (protracta, rubida and lecticularia), will undoubtedly provide a better understanding of the phylogenetic relationships and variability between and within North American triatomines, and macro- as well as micro-environmental determinants of their distributions.

\section{Conclusions}

Discriminant analysis of volatile compounds from disturbed bugs, and Brindley's and metasternal glands indicate significant differentiation among the three species of the phyllosoma complex. The two rose oxide isomers identified in females of all three species are novel and are the first monoterpenes with a tetrahydropyrane ring reported from the Triatominae. These compounds are not found in species of the dimidiata complex, which share a common ancestor. Behaviourally, disturbed T. pallidipennis and T. phyllosoma (allopatric) emitted similar compounds, while both were dissimilar to those from T. longipennis (sympatric with $T$. pallidipennis). VOCs have provided additional evidence to discriminate species within the phyllosoma complex, and between the former and those from the dimidiata complex, despite their recent divergence. Similar analyses of the remaining species of the phyllosoma complex and the other North American species complexes, will provide a more complete understanding of the phylogenetic relationships at species and complex levels.

\section{Abbreviations \\ BG: Brindley's glands; CRISP/INSP: Centro Regional de Investigación en Salud Pública/Instituto Nacional de Salud Pública; GC: Gas chromatograph; \\ GC-MS: Gas chromatograph-mass spectrometer; ITS: Internal transcribed spacer; MG: Metasternal glands; MS: Mass spectral; NZW rabbit: New Zealand White rabbit; PDMS-DVB: Polydimethylsiloxane-divinylbenzene; RAPD: Rapid amplification of polymorphic DNA; RH: Relative humidity; SPME: Solid-phase microextraction; VOC: Volatile organic compound}

\section{Acknowledgments}

We are grateful to the Consejo Nacional de Investigaciones Cientificas y Técnicas (CONICET-Argentina), for a scholarship to IJMC. We are grateful for the technical assistance of Antonio L. Morales (Instituto Nacional de Salud Pública, CRISP-INSP). We also thank Dr. Jocelyn G. Millar (Department of Entomology,

University of California, Riverside, USA) for supplying samples of 3, 5-dimethyl-2hexanone, and Dr. William F. Wood (Department of Chemistry, Humboldt State University, Arcata, CA, USA) for supplying samples of 3-methyl-2-pentanone and 3-methyl-2-hexanone used in this study.

\section{Funding}

This study was supported by funding from CONACyT Salud \#161405 and \#261006 to JMR.

\section{Availability of data and materials}

The datasets supporting the conclusions of this article are included within the article.

\section{Authors' contributions}

Study concept: IJMC, JCR, JMR and LCL. Collected the data: IJMC and LCL. Data analysis: IJMC, LCL, JCR and JMR. Wrote the manuscript: IJMC, JMR, JCR and LCL. All authors read and approved the final manuscript.

\section{Ethics approval and consent to participate}

The Ethics Committee (equivalent to IRB) of the Instituto Nacional de Salud Pública (INSP, (Cuernavaca, Morelos, Mexico) approved all human 
communication, participation and sampling protocols under the annual renewal of the permits \#727 and \#1063. Collection of bugs by the community or by technical team searching in or around houses, were carried out via verbal consent (following collective workshops and individual interview). The Biosafety Committee of the INSP (Comision de Bioseguridad, Cuernavaca, Morelos, Mexico), reviewed and approved animal care and use with permit numbers CB08-209, and renewed as CB12-020. Mexican national guidelines (NORMA Oficial Mexicana NOM-062-ZOO-1999, http:// www.fmvz.unam.mx/fmvz/principal/archivos/062ZOO.PDF) were adhered to for all animal (NZW rabbits) care and use. This care involved continuous review by competent professionals, diet supplements for iron and multivitamins, and a programmed use based on insect populations. This study did not collect endangered or protected species.

\section{Consent for publication}

Not applicable.

\section{Competing interests}

The authors declare that they have no competing interests.

\section{Publisher's Note}

Springer Nature remains neutral with regard to jurisdictional claims in published maps and institutional affiliations.

\section{Author details}

${ }^{1}$ Centro Regional de Investigación en Salud Pública, Instituto Nacional de Salud Pública (CRISP-INSP), Tapachula, Chiapas, Mexico. ${ }^{2}$ Laboratorio de Investigación en Triatominos, Centro de Referencia de Vectores, Ministerio de Salud de la Nación (CeReVe), Hospital Colonia, Pabellón Rawson calle s, /n Córdoba, Argentina. ${ }^{3}$ Grupo de Ecología y Manejo de Artrópodos, El Colegio de la Frontera Sur (ECOSUR), Tapachula, Chiapas, Mexico.

\section{Received: 7 September 2017 Accepted: 26 January 2018}

\section{Published online: 17 February 2018}

\section{References}

1. Steiger S, Schmitt T, Schaefer HM. The origin and dynamic evolution of chemical information transfer. Proc R Soc B Biol Sci. 2001;278:970-9.

2. Percy-Cunningham JE, MacDonald JA. Biology and ultrastructure of sex pheromone-producing glands. In: Prestwich GD, Blomquist GJ, editors. Pheromone biochemistry. Orlando, FL: Academic Press; 1987. p. 27-75.

3. Davis TS, Crippen TL, Hofstetter RW, Tomberlin JK. Microbial volatile emissions as insect semiochemicals. J Chem Ecol. 2013;39:840-59.

4. Bickford D, Lohman DJ, Sodhi NV, Ng PKL, Meier R, Winker K, et al. Cryptic species as a window on diversity and conservation. Trends Ecol Evol. 2007; 22:148-55.

5. Symonds MR, Elgar MA. The evolution of pheromone diversity. Trends Ecol Evol. 2008:23:220-8

6. Oldham NJ. Chemical studies on exocrine gland secretions and pheromones of some social insects. PhD Thesis, Keele University, UK; 1994. pp. 201.

7. Seybold SJ, Quilici DR, Tillman JA, Vanderwel D, Wood DL, Blomquist GJ. De novo biosynthesis of the aggregation pheromone components ipsenol and ipsdienol by the pine bark beetles Ips paraconfusus Lanier and Ips pini (Say) (Coleoptera: Scolytidae). Proc Natl Acad Sci USA. 1995;92:8393-7.

8. Kälin M, Barrett FM. Observations on the anatomy, histology, reléase site, and function of Brindley's glands in the blood-sucking bug, Rhodnius prolixus (Heteroptera: Reduviidae). Ann Entomol Soc Am. 1975;68:126-34.

9. Cruz-López L, Malo EA, Rojas JC, Morgan ED. Chemical ecology of triatomine bugs: vectors of Chagas disease. Med Vet Entomol. 2001;15:351-7.

10. Manrique $G$, Vitta $A C$, Ferreira RA, Zani $C L$, Unelius $C R$, Lazzari $C R$, et al. Chemical communication in Chagas disease vectors. Source, identity and potential function of volatiles released by the metasternal and Brindley's glands of Triatoma infestans adults. J Chem Ecol. 2006;32:2035-52.

11. May-Concha I, Rojas JC, Cruz-López L, Millar JG, Ramsey JM. Volatile compounds emitted by Triatoma dimidiata, a vector of Chagas disease: chemical identification and behavioural analysis. Med Vet Entomol. 2013;27:165-74

12. May-Concha IJ, Rojas-Leon JC, Cruz-López L, Ibarra-Cerdeña CN, Ramsey JM. Volatile compound diversity and conserved alarm behaviour in Triatoma dimidiata. Parasit Vectors. 2015;8:84-98.
13. Ibarra-Cerdeña CN, Zaldivar-Riveron A, Peterson AT, Sanchez-Cordero V, Ramsey JM. Phylogeny and niche conservatism in North and Central American triatomine bugs (Hemiptera: Reduviidae: Triatominae), vectors of Chagas' disease. PLoS Negl Trop Dis. 2014;8:e3266.

14. Pontes GB, Bohman B, Unelius CR, Lorenzo MG. Metasternal gland volatiles and sexual communication in the triatomine bug, Rhodnius prolixus. J Chem Ecol. 2008;34:450-7.

15. Vitta RAC, Bohman B, Unelius CR, Lorenzo MG. Behavioral and electrophysiological responses of Triatoma brasiliensis males to volatiles produced in the metasternal glands of females. J Chem Ecol. 2009:35:1212-21.

16. Lent H, Wygodzinsky P. Revision of the Triatominae (Hemiptera, Reduviidae), and their significance as vector of Chagas' disease. Bull Am Mus Nat Hist. 1979;163:123-520.

17. Zárate LG, Zárate RJ. A checklist of the Triatominae (Hemiptera: Reduviidae) of México. Intl J Entomol. 1985;27:102-27.

18. Ibarra-Cerdeña CN, Sánchez-Cordero V, Peterson AT, Ramsey JM. Ecology of North American Triatominae. Acta Trop. 2009;110:178-86.

19. Ramsey JM, Peterson AT, Carmona-Castro O, Moo-Llanes DA, Nakazawa Y, Butrick M, et al. Atlas of Mexican Triatominae (Reduviidae: Hemiptera) and vector transmission of Chagas disease. Mem Ins Oswaldo Cruz. 2015;110:339-52

20. Magallón E, Lozano F, Flores A, Bosseno MF, Brenière SF. Sylvatic Triatominae of the phyllosoma complex (Hemiptera: Reduviidae) around the community of Carrillo Puerto, Nayarit, Mexico. J Med Entomol. 2001;38:63840.

21. Ramsey JM, Gutierrez-Cabrera AE, Salgado-Ramírez K, Peterson AT, SánchezCordero V, Ibarra-Cerdeña CN. Ecological connectivity of Trypanosoma cruzi reservoirs and Triatoma pallidipennis host in an anthropogenic landscape with endemic Chagas disease. PLoS One. 2012;7:e46013.

22. Martínez-Tovar JG, Rodríguez-Rojas JJ, Arque-Chunga W, Lozano-Rendón JA, Ibarra-Juárez LA, Dávila-Barbosa JA, et al. Nuevos registros geográficos y notas de infección de Triatoma gerstaeckeri (Stål) y Triatoma rubida (Uhler) (Hemiptera: Reduviidae: Triatominae) en Nuevo León y Coahuila. México Acta Zool Mex. 2013;29:227-31.

23. López-Cancino SA, Tun-Ku E, De la Cruz-Felix HK, Ibarra-Cerdeña CN, IzetaAlberdi A, Pech-May A, et al. Landscape ecology of Trypanosoma cruzi in the southern Yucatan Peninsula. Acta Trop. 2015;151:58-72.

24. Ibarra-Cerdeña CN, Valiente-Banuet $L_{t}$ Sánchez-Cordero V, Stephens CR, Ramsey JM. Trypanosoma cruzi reservoir-triatomine vector co-occurrence networks reveal meta-community effects by synanthropic mammals on geographic dispersal. PeerJ. 2017;5:e3152.

25. Espinoza B, Martínez-Ibarra JA, Villalobos G, De la Torre P, Laclette JP, Martínez-Hernández F. Genetic variation of North American triatomines (Insecta: Hemiptera: Reduviidae): initial divergence between species and populations of Chagas disease vector. Am J Trop Hyg. 2013;88:275-84

26. Martínez-Hernández F, Martínez-Ibarra JA, Villalobos G, De la Torre P, Laclette JP, Alejandré-Aguilar R, et al. Natural crossbreeding between sympatric species of the phyllosoma complex (Insecta: Hemiptera: Reduviidae) indicate the existence of one species with morphologic and genetic variations. Am J Trop Med Hyg. 2010;82:74-82.

27. Martinez-Ibarra JA, Noqueda-Torres B, Licón-Trillo A, Alejandre-Aguilar R, Salazar-Schettino PM, Vences-Blanco MO. Biological aspects of crosses between Triatoma recurva (Stål), 1868 (Hemiptera: Reduviidae: Triatominae) and other members of the Phyllosoma complex. J Vector Ecol. 2015;40:117-22.

28. Valdez-Tah AR, Huicochea-Gómez L, Nazar-Beutelspacher A, Ortega-Canto J, Ramsey JM. La vulnerabilidad humana a la transmisión vectorial de Tripanosoma cruzi a través de los procesos de salud-enfermedad y la apropiación social del territorio. Salud Colectiva. 2015;11:191-210.

29. Pavia DL, Lampman GM, Kriz GS, Engel RG. Introduction to organic laboratory techniques, a microscale approach. Philadelphia: Saunders College Publishing; 1990. p. 879.

30. Dujardin JP Site: http://www.mpl.ird.fr/morphometrics/clic/index.html. 2004

31. May-Concha I, Guerenstein P, Ramsey JM, Rojas JC, Catalá S. Antennal phenotype of Mexican haplogroups of the Triatoma dimidiata complex vector of Chagas disease. Infect Genet Evol. 2016:40:73-9.

32. Marcilla A, Bargues MD, Ramsey JM, Magallon-Gastelum E, Salazar-Schettinom PM, Abad-Franch F, et al. The ITS-2 of the nuclear rDNA as a molecular marker for populations, species, and phylogenetic relationships in Triatominae (Hemiptera: Reduviidae), vectors of Chagas disease. Mol Phylogenet Evol. 2001;18:136-42.

33. Rossiter M, Staddon BW. 3-Methyl-2-hexanone from the bug Dipetalogaster maximus (Uhler) (Heteroptera; Reduviidae). Experientia. 1983;39:380-1. 
34. Hypša V, Tietz DF, Zrzavý J, Rego ROM, Galvao C, Jurberg J. Phylogeny and biogeography of Triatominae (Hemiptera: Reduviidae): molecular evidence of a new world origin of the Asiatic clade. Mol Phylogenet Evol. 2002;23:447-57.

35. Ohloff G. Chemie der Geruchs- und Geschmacksstoffe. In: Ohloff G, Kölbel H, Kurzendörfer P, Sackmann H, Demus D, editors. Angewandte Chemie. Fortschritte der Chemischen Forschung, vol. 12. Berlin: Springer Publishing; 1969. p. 185-251.

36. von Sydow E, Karlsson G. The aroma of black currants. IV. The influence of heat measured by instrumental methods. Lebensmittel-Wiss. u. Technol. 1971:4:54-8.

37. Nishimura K, Sakai T, Ogawa M, Hirose Y. Analysis of the volatile constituents of hamanasu absolute oil. Bull Chem Soc Jap. 1964;37:1407-9.

38. Yilmaztekin M. Analysis of volatile components of cape gooseberry (Physalis peruviana L.) grown in Turkey by HS-SPME and GC-MS. Sci World J. 2014:2014:1-8.

39. Vidari G, De Bernardi M, Pavan M, Ragozzino L. Rose oxide and iridiodal from Aromia moschata L. (Coleoptera: Cerambicidae). Tetrahedron Lett. 1973;41:4065-8.

40. Moore BP, Brown W. The chemistry of the metasternal gland secretion of the eucalypt longicorn, Phoracantha synonyma (Coleoptera: Cerambycidae). Aust J Chem. 1976:29:1365-74.

41. Ohmura W, Hishiyama S, Nakashima T, Kato A, Makihara H, Ohira T, et al. Chemical composition of the defensive secretion of the longhorned beetle, Chloridolum loochooanum. J Chem Ecol. 2009;35:250-5.

42. Cruz-López L, Malo AE, Morgan DE, Rincon M, Guzman M, Rojas JC. Mandibular gland secretion of Melipona beecheii: chemistry and behavior. J Chem Ecol. 2005;31:1621-32.

43. Dettner K. Chemosystematics and evolution of beetle chemical defenses. Annu Rev Entomol. 1987;32:17-48.

44. Seybold SJ. Role of chirality in olfactory-directed behaviour: aggregation of pine engraver beetles in the genius Ips (Coleoptera: Scolytidae). J Chem Ecol. 1993;19:1809-31.

45. Blum MS. Chemical defenses of arthropods. New York, NY, USA: Academic Press; 1981. p. 562.

46. Juárez P, Brenner R. Bioquimica del ciclo evolutivo de Triatoma infestans (vinchuca). V. Emisión de ácidos grasos volátiles. Acta Fisiol Latinoamericana. 1981;31:113-7

47. Cruz-López L, Morgan ED, Ondarza RN. Brindley's gland exocrine products of Triatoma infestans. Med Vet Entomol. 1995;9:403-6.

48. Guerenstein PG, Guerin PM. A comparison of volatiles emitted by adults of three triatomine species. Entomol Exp Appl. 2004;111:151-5.

49. Apps PJ, Viljoen HW, Pretorius V. Aggregation pheromones of the bont tick Amblyomma hebraeum: identification of candidates for bioassay. Onderstepoort J Vet Res. 1988;55:135-7.

50. Schofield CJ. The behaviour of Triatominae (Hemiptera: Reduviidae): a review. Bull Entomol Res. 1979;69:363-79.

51. Ward JP. A comparison of the behavioural responses of the haematophagous bug, Triatoma infestans to synthetic homologues of two naturally occurring chemicals ( $n$ - and isobutyric acid). Physiol Entomol. 1981;6:325-9.

52. Minoli S, Palottini F, Crespo JG, Manrique G. The main component of an alarm pheromone of kissing bugs plays multiple roles in the cognitive modulation of the escape response. Front Behav Neurosci. 2013;77:1-10.

53. Palottini F, Manrique G. Compounds released by disturbed adults of the haematophagous bug Triatoma infestans (Hemiptera: Reduviidae): behavioural effects of single compounds and binary mixtures. Physiol Entomol. 2016;41:234-40

54. Rojas JC, Rios-Candelaria E, Cruz-Lopez L, Santiesteban A, BondCompean JG, Brindis $Y$, et al. A reinvestigation of Brindley's gland exocrine compound of Rhodnius prolixus (Hemiptera: Reduviidae). J Med Entomol. 2002;39:256-65.

55. González-Audino GP, Alzogaray RA, Vannesa C, Masuh H, Fontán A, Gatti P, et al. Volatile compounds secreted by Brindley's glands of adult Triatoma infestans: identification and biological activity of previously unidentified compounds. J Vect Ecol. 2006;32:75-82.

56. Germinara GS, De Cristofaro A, Rotundo G. Behavioral responses of adult Sitophilus granarius to individual cereal volatiles. J Chem Ecol. 2008;34:523-9.

57. Brenière SF, Taveira B, Bosseno MF, Ordoñez R, Lozano-Kasten F, MagallonGastellum E, et al. Preliminary results of random amplification of polymorphic DNA among Triatominae of the phyllosoma complex (Hemiptera, Reduviidae). Mem Inst Oswaldo Cruz. 2003;98:1033-8.
58. Martínez HF, Villalobos CG, Ceballos AM, De la Torre P, Laclette JP, Alejandre-Aguilar R, et al. Phylogenetic analysis of Triatominae (Hemiptera: Reduviidae) species of epidemiological importance in the transmission of Chagas disease: nuclear DNA vs mitochondrial DNA as molecular markers. Mol Phylogenet Evol. 2006;41:279-87.

59. Juárez MP, Blomquist GJ. Cuticular hydrocarbons of Triatoma infestans and T. mazzottii. Comp Biochem Physiol. 1993;106:667-74.

60. Juárez MP, Carlson DA, Salazar-Schettino PM, Mijailovski S, Rojas G. Cuticular hydrocarbons of Chagas disease vectors in Mexico. Mem Inst Oswaldo Cruz. 2002;97:819-27.

61. Catalá S, Sachetto C, Moreno M, Rosales R, Salazar-Schettino PM, Gorla D. Antennal phenotype of Triatoma dimidiata populations and its relationship with species of phyllosoma and protracta complexes. J Med Entomol. 2005; 42:719-25.

62. Calderón-Fernández GM, Juárez P. Cuticular hydrocarbons of the Triatome sordida species subcomplex (Hemiptera: Reduviidae). Mem Inst Oswaldo Cruz. 2013;108:778-84

\section{Submit your next manuscript to BioMed Central and we will help you at every step:}

- We accept pre-submission inquiries

- Our selector tool helps you to find the most relevant journal

- We provide round the clock customer support

- Convenient online submission

- Thorough peer review

- Inclusion in PubMed and all major indexing services

- Maximum visibility for your research

Submit your manuscript at www.biomedcentral.com/submit

) Biomed Central 